\title{
Remote Sensing Spatial and Temporal Earth Observations in Pakistan
}

\author{
Jahangir Khan ${ }^{1}$ and Pengxin Wang ${ }^{2 *}$ \\ ${ }^{1}$ Faculty of Computer Science and Information Technology, Sarhad University of Science and Information Technology, Peshawar 25000, Pakistan \\ ${ }_{1,2}$ Key Laboratory of Remote Sensing for Agri-Hazards of Ministry of Agriculture, College of Information and Electrical Engineering, China Agricultural \\ University, Beijing 100083, P R of China
}

Received: 制: July 23, 2018; Published: 些 July 30, 2018

*Corresponding author: Pengxin Wang, Key Laboratory of Remote Sensing for Agri-Hazards of Ministry of Agriculture, College of Information and Electrical Engineering, China Agricultural University, Beijing 100083, P R of China.

Abbreviations: ENSO: El Niño-Southern Oscillation; SST: Sea Surface Temperature; NDVI: Normalized Difference Vegetation Index; LST: Land Surface Temperature; MODIS: Moderate Resolution Imaging Spectroradiometer; VTCI: Vegetation Temperature Condition Index

\section{SPATIAL OBSERVATIONS}

The global warming causes the global climate changes, and with this consequence, Kreft (2015) listed Pakistan on number-eight of the most affected ten-countries from 1995-2014 in the world [1,2] wrap up on the basis of observed changes in global aridity from 1923-2010 and suggested severe and widespread droughts in the next 30-90 years due to low rainfall and/or increased evaporation with global and regional variations in ENSO (El Niño-Southern Oscillation) by tropical sea surface temperature (SST) and unforced natural variations. In Pakistan, the adverse events (drought and flood) occur mainly due to the deficit or excess of rains coming from southwest monsoons, which are associated with La-Nina and El-Nino events. Pakistan lies in the south Asian region, where the reliance on ground data is not sufficient for drought monitoring. This is due to the lack of reliable and complete data and proper information network systems, and the lower availability of weather-stations in the region. In contrast, satellite remote sensing spatial and temporal observations has been extensively used over the long-ago 20 plus years for the land cover changes, including drought conditions.

To determine and monitor the regional drought and is mainly based on an index (e.g. vegetation temperature condition index) that is a function of spectral vegetation index termed as normalized difference vegetation index (NDVI) and land surface temperature (LST) to investigate the dry and wet spells in the study region like Punjab, Pakistan. The VTCI approach presents the multi-year spatial and temporal observation for drought conditions using the remote sensing EOS's Moderate Resolution Imaging Spectroradiometer (MODIS) data products to acquire the land surface conditions during the winter-wheat-crop season in the cropland of the plain under rain-fed and irrigated conditions for the 5-yr periods during
2010-2014 [3]. In the elucidation of [4] prediction during 19952015, Pakistan experienced the long-lasting severe drought during 1998-2002 and the worst flood in 2010 so for this is obvious to explore the drought conditions in the plain of Punjab [5]. The spatial and temporal observations during the 5 -yr periods persist in the south and southeast of plain and slightly expand in the northeast of the plain.

During January to June, the exceptional drought was introduced over the four corners and expanded into parts of south, southeast, center, northeast, and northwest of the plain. In addition, extreme drought expanded in parts of Multan (south of the plain), Faisalabad (center of the plain) in comparison to the Lahore (northeast of the plain) during the 5-yr periods from 2010-2014. On the northern and eastern periphery of the plain and southwest drought areas, improvement or removal of drought is expected due to enough precipitation in the northeast of the plain, and show the water scarcity in the south of the region during the winter-wheat-crop. The VTCI observations for the drought conditions over the plain expanded and worsened over much of the south lower plains as well as in southeast of the plain, while conditions improved in parts of northeast and northwest due to enough rainfall in the green-up stage of winter-wheat-crop. Generally, the annual planting window for Punjab's winter-wheat-crop extends from October through early December of wheat crop development by mid-January.

And the wheat flowering stage and grain filling come about from early-February to late-March, whereas, the harvesting period range from April to June. Therefore, the selected study spatial and temporal observation was recorded from January to June for the 5-yr period during winter-wheat-crop season to determine the dry and wet conditions in the cropland of Punjab. The temporal 
and spatial observations reveal that the south and center of the plain expose to drought in contrast to the northeast with high occurrences of drought, whereas, the northeast indicates most of the normal conditions of drought in the plain. This illustrate that during the 5-yr period of winter-wheat-crop seasons, in the year of 2010 and 2011 the decreased was calculated with 2846 and 2737 yield per hectare in KG's from the average yield production under both rainfed and irrigated conditions in the Plain. Before and after the flood inception the wheat crop area was 6691.0 hectares in 2010-2011, whereas, in 2011-2012 it was decreased to 6482.9 hectares. This shows that the flood (2010) affects the area and the production, and was decreased from 19.041 to 17.7389 million tonnes.

This demonstrates the seasonal rainfall and flood events as well as the drought conditions during the winter-wheat-crop season in the plain of Punjab in the 5-yr period. This reflects the agricultural and hydrological impact in the plain and shows that VTCI is favorable for the dry and wet spells during the winter-wheat-crop seasons and also reveals the effectiveness of multi-year MODIS VTCI approach observations for the determination of drought conditions and flood events in the given periods over the plain of Punjab. Therefore, for the spatial and temporal observations, the obtained vegetation and temperature related drought index (VTCI) results are in a good agreement for drought monitoring over the cropland of Punjab, Pakistan. Thus, the findings of this study are likely to be relevant for the other regions or provinces of Pakistan as well as for other countries having the same geographical profiles. The results of this study can also help the relevant government departments at all levels (national, provincial, and local levels), academic research and the policymakers to design comprehensive drought policies before implementing any plan of actions keeping in view the regional variations or differences.

\section{References}

1. Dai A (2011) Characteristics and trends in various forms of the Palmer drought severity Index during 1900-2008. Journal of Geophysical Research: Atmospheres 116(12).

2. Dai A (2012) Increasing drought under global warming in observations and models. Nature Climate Change 3(1): 52-58.

3. Khan J, Wang P, Xie Y, Wang L, Li L (2018) Mapping MODIS LST NDVI Imagery for Drought Monitoring in Punjab Pakistan. IEEE Access 6: 19898-19911.

4. Kreft S, Eckstein D, Dorsch L, Fischer L (2015) Global climate risk index 2016: who suffers most from extreme weather events, weather-related loss events in 2014 and 1995 to 2014. electronic version, Germanwatch Nord-Süd Initiative.

5. Glanemann N, Willner S, Christian 0 (2017) Climate change and trade networks.

\section{ISSN: 2574-1241}

DOI: $10.26717 / B J S T R .2018 .07 .001498$

Pengxin Wang. Biomed J Sci \& Tech Res

(C) (7) This work is licensed under Creative

Submission Link: https://biomedres.us/submit-manuscript.php

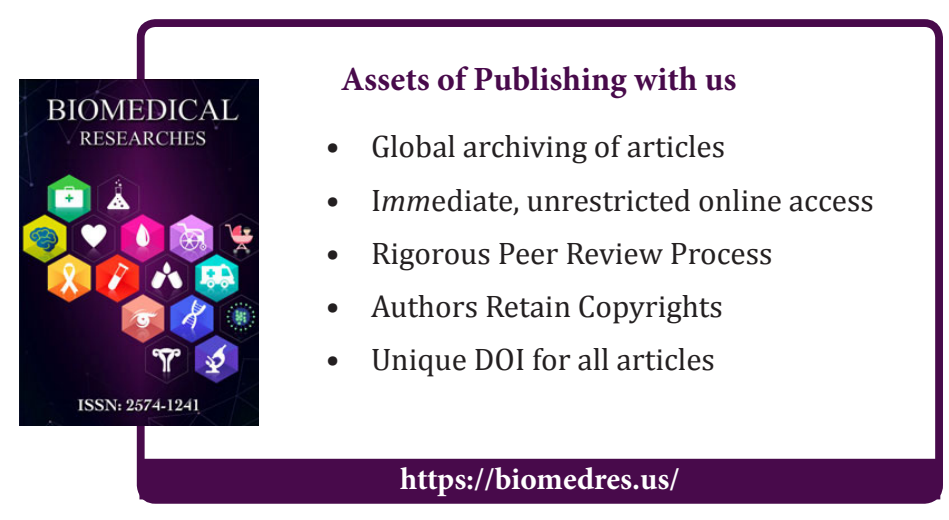

